\title{
Kindness and Compassion Practice
}

\author{
Robert Marx ${ }^{1}$ (1) \\ Accepted: 4 February 2022 \\ (c) The Author(s), under exclusive licence to Springer Science+Business Media, LLC, part of Springer Nature 2022
}

Many of us come up against some kind of difficulty at some point when we encounter and persist with Kindness and Compassion practices (KCP). Maybe the practice feels artificial, jarring, unrelatable or unnecessary; or the perceived requirement to produce certain mind states feels effortful and unnatural. The people who are the objects of the practice may feel unworthy of kindness or compassion. Perhaps the sense of ourselves that the practice generates is disturbing, or just not what we were expecting or wanting.

Traditionally, KCP can often be taught in a structure in which kindness or compassion is directed to people we like, feel indifferent to, dislike, ourselves and everyone. This can make it feel like it's a practice about wishing or sending kindness or compassion to people out there. This can create problems when we bring up people who have perpetrated heinous acts, such as dictators or abusers, or people who have beliefs that are diametrically opposed to ours, or often the difficulty is feeling we ourselves are worthy of receiving something good. However, those people (including the particular version of ourselves we have in mind), mostly aren't actually there when we are doing the practice; rather, what we encounter in the practice is our minds. What we are working with is our reactive mind states evoked by the meanings we associate with our construction of those people. The traditional structure of $\mathrm{KCP}$ is analogous to the structure of vedana (feeling tones) practice in which we work with our reactivity to experience that is pleasant, unpleasant or neither pleasant nor unpleasant; it is just that in KCP, the emotions and thoughts we are working with are often made more vivid when they are associated with real people.

We might investigate the cycle in which vedana is positioned in traditional Buddhist texts (pratītyasamutpāda),

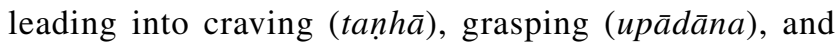
becoming (bhava). KCP can support non-reactivity by

Robert Marx

robert.marx@spft.nhs.uk

1 Sussex Mindfulness Centre, Sussex Partnership NHS Foundation Trust, Brighton General Hospital, Elm Grove, Brighton BN2 3EW, UK noticing the chain of reactions and then holding their energy in a kind or compassionate space. For example, in the moment of starting to argue with a colleague or a family member, directing compassion to our own suffering in that moment, the suffering of the other person and the suffering inherent in the stuckness of the situation, can interrupt, dilute and even replace the frustration, irritation or deflation that might be fuelling an automatic pattern. Kindness can remind us of our shared desire to be happy and feel safe in that interaction. Just as in Mindfulness-based Cognitive Therapy (MBCT), the insight that "thoughts are not facts" can free us from having to believe and act on our thoughts, so KCP can free us from having to believe the demand our feelings appear to make on us to act impulsively from their energy. The emphasis on kindness and compassion can shift our perspective on a particular situation, essentially by helping us see beyond ourselves. When we connect with the bigger picture opened to us by our awareness of the needs, fears and feelings of others, or by a more compassionate take on ourselves, we can loosen our misplaced conviction in the rightness of our viewpoint and in the compulsion to act from it. That can soften the polarisation of views and make a constructive conversation more possible.

We know that mindfulness practice is about developing a particular relationship with all of our experience, rather than changing the content of it. However, with $\mathrm{KCP}$, it can start to feel as if the content of experience is important and that some kinds of feelings or states indicate success in the practice (kind, loving feelings) and others (shame, anger, blankness, indifference) can indicate failure. It is then easy for us to get busy and become outcome-oriented, trying to change one for the other. However, there is no feeling we could have in $\mathrm{KCP}$ that could mean that we had failed in this practice, and no feeling that we need to change to do this practice. Any and all experience is a valid object of KCP. Indeed, if the content is (manageably) heavy and difficult, that is an ideal object of KCP as we are learning to befriend the difficult, hold the unwelcome with kindness, and inhabit a bigger space than that unwelcome experience. It's hard to learn that we can do that without some unwelcome experience. 
It may feel as if this is what we do anyway in mindfulness (śamatha/vipassana) practice but the difference between a warm attention and an indifferent or critical one can be significant. Although we may have an idea that it's only mindfulness if it is warm attention, and as teachers we spend time offering guidance on attitude as well as attention, still it is almost inevitable that initially at least, we will fall into the same flavour of noticing that we tend to talk to and relate to ourselves with. If we have a tendency to become depressed, that is likely to have a critical element to it. "Just noticing" is a blank canvas onto which we can project anything, and until we have had an experience of a warmer way of relating, the self-critical tone accompanying the noticing will not feel problematic; it will just feel so normal and true that we may not even notice it. Sometimes, it may be enough to experience the warmth with which the teacher relates to us and start to borrow that to relate to ourselves until it becomes our home. However, very often it can be helpful to do some explicit work to help notice the critical stance and help to soften it.

Sometimes the experience evoked by KCP is too intense and overwhelming to work with and then a re-focusing elsewhere is the most compassionate response. David Treleaven, and others have in the last few years in particular brought greater understanding to the ways in which mindfulness practice, including $\mathrm{KCP}$, can trigger reactions to trauma that require particular trauma-sensitive responses, which could include stopping the practice and doing something entirely different and more grounding. KCP invites us to be with vulnerability and this is exactly what we have had to learn to protect if we have experienced developmental or other trauma. If we have had to learn to be vigilant against attack, then letting down our guard may feel unsafe and threatening. Whilst KCP can be triggering and unhelpful if we are not yet sufficiently resourced to work with the reactions that come from it, the kindness and compassion can also be an invaluable container that allows us to go into the difficult places and hold the emotions found there. Working with challenging reactions to practice, identified by Chris Germer as "backdraft", can be a core component of the healing process if the intensity is within manageable parameters.

We might think that KCP ask us to cultivate something and are therefore different from mindfulness practices that simply invite us to be with our experience. We tend to think that in mindfulness of the breathing practice, nothing is being added as we are simply returning our wandering attention to the already existing sensations of breathing. However, we could see KCP in the same way. In KCP, we return our attention to a particular point, but in this case the anchor is not the breath but rather a benevolent intention or space. In this case, distraction might include the attention turning cold or critical which could be a signal to renew the intention of warmth. As long as we have this anchor, we can direct it to anything that arises, whether it is the texture and experience of our own unmet needs, or the person who presses our buttons, or the suffering of animals. In this way, our KCP can be a warm Guest House of hospitality for whomsoever enters. Conversely, whilst it may feel as if nothing is being added in a mindfulness of breath practice, actually attentional focus is being cultivated, just as in KCP, kind or compassionate attention is being cultivated.

The objection to KCP of not being able to feel kindness or compassion can lead to other challenges, such as the perceived need to (a) feel something in particular, (b) cope with negative judgments about what can then feel like our defectiveness in being unable to feel what we expected to feel and (c) try to change so-called "negative" feelings into "nicer" ones. The most important response to this objection is that KCP is not predominantly about feeling something; warm emotions are sometimes a side-effect of KCP but the practice is about warming our orientation, our intentionality. If having enough of certain feelings is the standard around which the practice is judged, the practice is not based on firm ground. This is like a film that moves us without a well-built basis for being moved: the emotion might feel intense but there is also a flimsiness to its unearned nature.

Nevertheless, to feel something is helpful in KCP in empathising with the experience of others and attuning to one's own feelings. Sometimes, we cannot connect with our more tender emotions. I notice I find it harder to resonate with others when I am tired, stressed or very busy. At such times, my reduced capacity for empathy may be serving to protect me from not becoming overwhelmed with more than I can handle at a time when I am not feeling very resourced. This is not a failing and does not mean anything fundamental about who I am. The experience of feeling nothing, and any narratives that proliferate from it about what that means, can be the focus of our mindful attention in KCP, inviting curiosity and self-compassion for what that is like, rather than judgment, in a manner analogous to bringing attention to a body part that has no sensation in a body scan practice. Empathy and compassion can be cultivated; that is why they are practised; we simply start where we are.

At other times, it can be hard to empathise with people whose situations seem far removed from our own, whether that is due to demographics or context. It may help to remember that we do not really ever directly know what someone else is feeling. All we have to go on is an inference from our own feelings. Some situations we might bring into our compassion practice, such as torture by an authoritarian regime, fleeing a war-torn country or dying in pain may be far from our own experience. We need to try to make a bridge from accounts of others we may have heard or read about, and our own experience of cold, hunger, terror, cruelty or pain via whatever empathic imagination or sense of common humanity we can find, knowing we will probably 
never really have reached anywhere near the full horror of these other situations. However, the efforts made to do this work are preferable to the alternative.

It can be helpful to keep our expectations very small-scale and real. Kindness may be the difference in one moment between making that insensitive remark and holding back; between letting in the driver into the stream of traffic or carrying on; between offering to make someone a hot drink and not offering. And then these kinds of experience, whether we were the agent or recipient of them, can be used in the practice to reconnect to a kind and compassionate orientation. Anything that shifts our perspective on our experience just a tiny bit is useful. This can equally be done by bringing to mind an image of a person who in some way embodies kindness or compassion for us (again small-scale is beautiful; we do not need saints), or an animal that evokes tenderness and warmth; or using symbols of warmth, like the sun; or the physical experience of the heart area of the body; or repeating over and over a word like "kind", or the more traditional phrases often used in KCP or more personalised, meaningful versions of them. These images, memories, words or sensations can then become our material for KCP, and the intention behind them the anchor that holds the content of our experience.

\section{Intentionality as the Heart of KCP}

In the Mindful Self-Compassion programme, we invite people to cultivate good will, not good feeling. In other words, it is about an intention or an orientation to our experience, not about trying to generate some particular feeling state or outcome. Intentions are more durable than feelings. You can decide to come back to an intention, regardless of what you are feeling. Shakespeare referred to love in terms of this kind of intentionality, as "an ever fixed mark/That looks on tempests and is never shaken". The intention remains our anchor and we return there over and over, whatever the content of our experience. In the Mahayana Buddhist tradition, coming back to the Bodhisattva Vow is an intentional anchor that is not dependent on whether or not we feel like making the vow.

There are however different reasons why we might do $\mathrm{KCP}$ and therefore different types of intentionality, depending on the tradition or framework within which the practice is contextualised. Here are four types of intention that can be used in KCP:

First, to feel happier: either to manage challenging, depressive or shame-based states by developing a warmer internal commentary, softening self-critical and self-punishing ways of relating; and/or to encourage flourishing and well-being: to feel a greater sense of appreciation or connection, and to identify our deeper needs and respond wholesomely to them. This is the territory of many secular kindness and compassion-oriented (and mindfulness) programmes.

Second, to become more resilient and stable in our orientation to experience: to develop the capacity for equanimity by being able to hold what is difficult, and to be thereby less reactive and blown around by turbulent and difficult experiences and the states they generate. This is also found in secular programmes but equanimity is also cultivated as one in the series of four divine abidings (brahma vihara) in the Buddhist sequence that also includes kindness and compassion. Equanimity is not separate from KCP: it is the quality that is needed to ensure kindness and compassion do not become attachment, partiality, or otherwise self-serving.

Third, to strengthen the commitment and capacity to benefit others: based on a recognition that we share a common desire to be happy and well, we are driven by a desire to cultivate good will indiscriminately, unconstrained by personal feelings of liking or disliking. This is found in some secular programmes and many religious traditions (e.g. Rumi's Guest House, the Sermon on the Mount) and is the hallmark of Mahayana Buddhist practice expressed in the bodhisattva vow, to never give up on any sentient being, whatever feelings they evoke in us but to remain open and responsive to benefit beings in whatever way they might need.

Fourth, to loosen self-cherishing: KCP helps us to change the fulcrum away from self-preoccupation so that not everything is driven and evaluated on the basis of the extent to which it makes us feel safe, comfortable or affirmed; it thereby allows us to start to free ourselves from the misguided experiential structure of appropriating all experience into a constructed and ultimately baseless sense of "mine", which from a Buddhist perspective, is the cause of our sense of separation from others and of our suffering.

What all of these intentions do is provide us with an anchor to return to when we are caught by automatic patterns of thinking, feeling or reacting that create trouble for us. They give us a way to respond to whatever we feel in $\mathrm{KCP}$, rather than responding from what we feel. The difference between these layers of intentionality hinges on assumptions about the self. The intentions start from a position in which the self is considered a real and valid object of kindness and compassion; they move towards a position where the suffering caused by our preoccupation with the self as real and valid is the most appropriate focus of our compassion.

Different types of intentionality may be called for at different times. When we are under-resourced and under a great 
deal of pressure, to repeatedly ignore the self-care that is at the heart of the first intention above may become an unwise "spiritual bypassing" that could lead to further problems down the road. On the other hand, to see the first intention as the extent of what KCP can do is to miss the compassion expressed in the third and fourth intentions that are seeking to remove structural obstacles to the deeper layers of our suffering. The practice of tong len (giving away to others what we want and absorbing from others what we do not want) combines all intentions. On the surface, it is a "relative truth" practice, working within the sense of a subject seeking to benefit an object; however, it is also a "wisdom" practice, working as it does on reversing our habitual self-serving instincts and loosening our rigid sense of "me" and "other".

What feel like obstacles to KCP are common and can become fruitful compost for the practice. They are mostly not reasons to give up on KCP but rather opportunities to clarify what we are doing and why, and to adapt the practice so it becomes workable. It can be helpful to try to discern what we need and what is helpful for us and to use the practice to support that, staying close to where we are and releasing the need to have any particular experience.

Acknowledgements With thanks to Taravajra, Hester O Connor, James Low, Richard Gilpin and Sarah Marx for their comments on previous drafts of this paper.

\section{Declarations}

Ethics Approval The manuscript does not contain clinical studies or patient data.

Conflict of Interest The author declares no competing interests.

Publisher's Note Springer Nature remains neutral with regard to jurisdictional claims in published maps and institutional affiliations. 